\title{
Donor specific antibodies after transplantation
}

Platt JL, Cascalho M. Donor specific antibodies after transplantation. Pediatr Transplantation 2011: 15: 686-690. (C) 2011 John Wiley \& Sons A/S.

Abstract: The detection of donor-specific antibodies after organ transplantation might provide an incisive way to monitor allo-specific immunity and predict graft outcome. Still, the availability of new assays for these antibodies prompts us to pose some questions about results that might be observed. These questions include whether the antibodies detected in the blood are a sensitive measure of alloimmunity, whether the detected antibodies are truly specific for the donor and whether they are noxious for the graft. Here, we explain why answers to these questions might interest the basic scientist and clinician.

\author{
Jeffrey L. Platt and Marilia Cascalho \\ Departments of Surgery and Microbiology and \\ Immunology, University of Michigan, \\ Ann Arbor, MI, USA \\ Key words: donor specific antibodies - alloantibodies \\ - accommodation - antibody mediated rejection - \\ alloimmunity \\ Jeffrey L. Platt, MD, Departments of Surgery and \\ Microbiology and Immunology, University of \\ Michigan, 109 Zina Pitcher Place, Ann Arbor, Ml \\ 48109-2200, USA \\ Tel.: 7346156819 \\ Fax: 7346157141 \\ E-mail: plattj|@umich.edu \\ Accepted for publication 25 October 2010
}

The functions of most organ systems can be measured precisely, and individuals in a population can be ranked according to function. In striking contrast, the functions of the immune system cannot be measured precisely nor can one rank the immunologic fitness of individuals in a population. The inability to measure immune function has the greatest impact on children who undergo transplantation. Such children are treated with regimens of immunosuppression that impair growth, vitality, and resistance to infection and would derive the greatest benefit if the regimen could be adjusted to suit their needs. Recently devised technologies and older technologies newly interpreted for detecting and measuring donor-specific antibodies in those awaiting transplantation might be adapted to fill that void if the technologies so applied after transplantation truly represent the level of immunity to, and predict the outcome of, the graft.

The detection prior to transplantation of antibodies specific for a potential transplant donor has proven invaluable. High levels of these antibodies, especially complement-fixing antibodies, in a potential recipient presage hyperacute rejection (1); low levels may anticipate antibody-mediated rejection (2). We previously explored in detail how those antibodies might inflict injury on organ transplants $(3,4)$ and will not comment here on this subject.
Basic scientists, such as us, also find the de novo development of donor-specific antibodies after the transplantation of interest. From our perspective, the interest and importance of donor-specific antibodies arising after transplantation stems from basic and practical questions about the assays used and the meaning of positive and negative results. We shall discuss some of those questions in this communication. As we are not engaged in clinical practice, we realize our remarks may betray some naiveté. We hope readers will take that to indicate a need to communicate the results of clinical observations to the broader scientific community.

\section{Are donor-specific antibodies a sensetive index of immunity?}

We first would ask whether donor-specific antibodies are a sensitive index of immunity to transplantation. Certainly, in the experimental setting, antibodies to major histocompatibility antigens are sensitive, specific, and reliable, as these antibodies allowed the discovery and mapping of the major histocompatibility locus $(5,6)$. We are concerned, however, that after organ transplantation one might find that some histocompatibility antigens do not incite humoral immunity, at least not continuously, or that antibodies produced against some antigens might be absorbed to the graft and hence are scarcely 
detectable or not detectable at all. Unfortunately, with a graft in place, we think distinguishing the absence of response on the one hand from absorption of responding antibodies on the other based on antibody levels in the blood is difficult or impossible. The clinical experience that second transplants with a negative cross-match are at greater risk than first transplants suggests that sensitization occurs regardless of whether donorspecific antibodies are produced. However, the greater risk might reflect variations in immune fitness or responsiveness among individuals in a population rather than sensitization per se. Consistent with the later explanation (variations in capacity to mount any immune response rather than prior exposure to a given antigen), Farney et al. (7) showed that outcome of second transplants sharing HLA antigens with first transplants is no different than the outcome of second transplants with entirely different HLA types.

Regardless of whether all or only some HLA mismatches provoke immunity, experimental kidney transplants, especially, appear capable of absorbing large amounts of donor-specific antibodies, leaving little or no detectable antigraft antibody in the blood. We can offer examples from experimental transplants between species that represent the extreme of humoral responses to transplantation (4). Fig. 1 shows the results of one experiment that we have repeated in many systems (8). A kidney of a squirrel monkey, which expresses Gal $\alpha 1-3 \mathrm{Gal}$, is perfused by the blood of a baboon, which does not express that sugar and makes large amounts of antibody against it [anti-Gal $\alpha 1-3 \mathrm{Gal}$ antibodies represent $1-2 \%$ of immunoglobulin in the blood (9)]. Perfusion of the kidney for only one half hour removes more than $90 \%$ of anti-Gal $\alpha 1-3 \mathrm{Gal}$ antibody and indeed of all xenoreactive antibody from the blood of the baboon. Fig. 2 shows another experiment in which the heart of a pig expressing human complement regulatory proteins is transplanted into a baboon. Rejection of the heart can be shown to be caused by
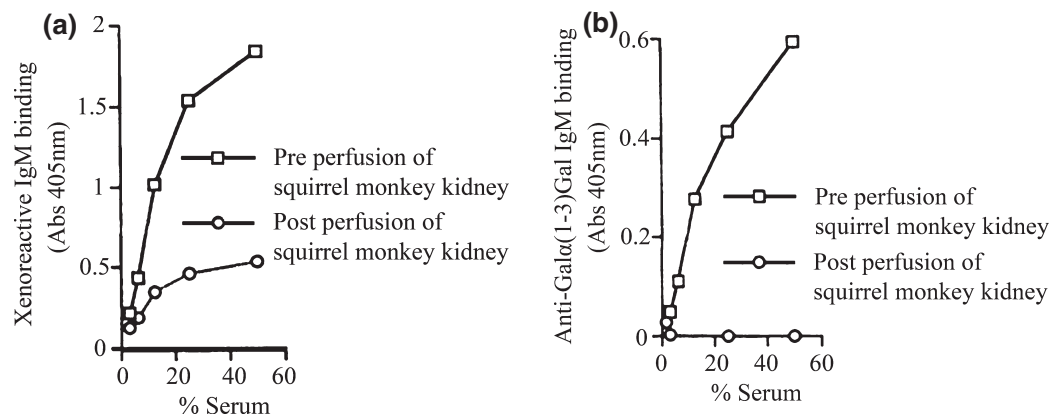

Fig. 1. Absorption of xenoreactive and anti-Gal $\alpha 1-3 \mathrm{Gal}$ antibodies during perfusion of xenogeneic kidneys. Absorption of total xenoreactive (a) and anti-Gal $\alpha 1-3 \mathrm{Gal}$ antibodies (b) from baboon blood during perfusion of xenogeneic organs. Squirrel monkey kidneys were connected through ex vivo circuits with the circulation of baboons, and blood was sampled before and after passage through the kidneys. Total xenoreactive and anti-Gal 1 1-3Gal antibodies were measured by ELISA on the basis of binding to cultured porcine endothelial cells. Adapted from Figure 3, Collins et al. (8), copyright 1995, The American Association of Immunologists, Inc.
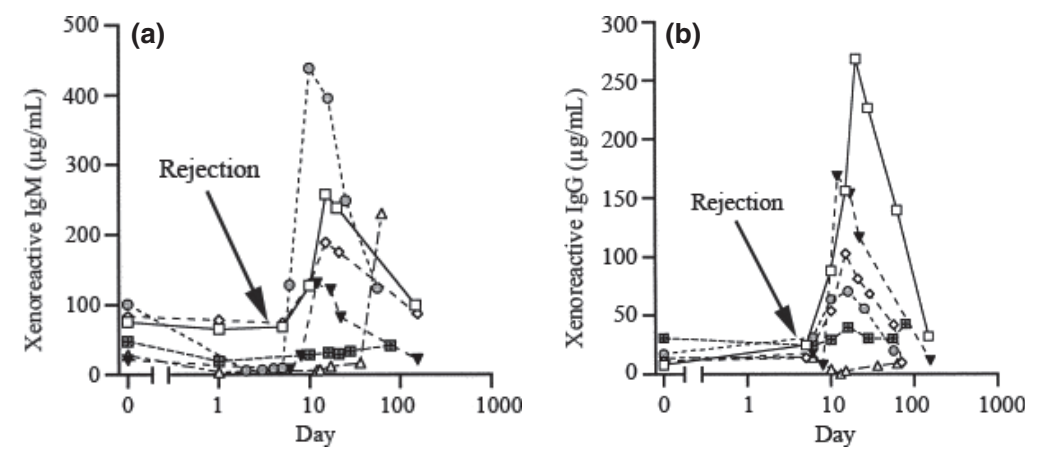

Fig. 2. Concentration of xenoreactive $\operatorname{IgM}$ (a) and $\operatorname{IgG}$ (b) in baboons after xenotransplantation. Xenoreactive $\operatorname{IgG}$ was measured by ELISA after transplantation of swine hearts into baboons. In each of six baboons, xenoreactive IgG levels remained at baseline until day 10-15 when the xenografts were removed. Impaired contractility and severe antibody-mediated rejection were observed by day 7 (arrow). Adapted from Figure 3, McCurry et al. (28), copyright 1997, with permission from Elsevier. 
anti-Gal $\alpha 1-3 \mathrm{Gal}$ antibodies, as removal of those antibodies prevents rejection $(10,11)$. In this experiment, no anti-Gal $\alpha 1-3 \mathrm{Gal}$ antibody appears in the blood until the organ is rejected and removed from the baboon.

In these models at least, hearts and kidneys can be shown to remove all or nearly all donorspecific antibody. Whether kidneys or other organs can remove all or nearly all anti-HLA antibodies is not known. As some HLA antigens are expressed at relatively low levels, it is possible that quantitative removal of antibodies against those antigens might not occur. But then, one would rightly question whether the antigen density suffices to serve as a target for a pathologically significant response.

\section{Is the appearance of donor-specific antibodies in the blood an early or late sign of humoral immunity to a graft?}

If antibody-mediated rejection is mediated by antibodies, then obviously those antibodies must be produced before rejection occurs. Moreover, as the presence of donor-specific antibodies in the blood of transplant recipients correlates with antibody-mediated rejection, one might expect that the antibodies detected were produced some finite time before tissue injury occurs and that those antibodies cause rejection. However, we question some of these obvious points and think substantiation is warranted.

If donor-specific antibodies can be absorbed in large measure by an organ transplant, then tissue injury and rejection might occur in subjects in whom donor-specific antibodies are undetectable in the blood. Further, as the absorption of antibodies by an organ depends on blood flow to the organ, the presence of donor-specific antibodies might be first detected or might dramatically increase only when blood flow decreases late in the course of rejection. Hence, donor-specific antibodies might not represent an early sign of rejection but rather might represent a relatively late stage of injury and rejection. In this setting, donor-specific antibodies mark tissue injury rather than humoral immunity. Fig. 2 depicting the levels of anti-Gal $\alpha 1-3$ Gal antibodies in the blood of a baboon following transplantation with a swine heart depicts such a condition. The arrow in the figure denotes the time when severe antibody-mediated rejection is detected in a biopsy. At this time, the level of anti-Gal $\alpha 1-3 \mathrm{Gal}$ antibodies has barely increased above baseline. Only when the rejected organ is removed do those antibodies substantially exceed baseline. A similar observation was made years ago (12), although whether injury and rejection were caused by cellular or antibody-mediated injury was not investigated. Still, in these models as in our models of antibody-mediated rejection, the transplant must undergo severe injury before antibodies are detected in the blood.

We think the question of whether donorspecific antibodies represent an early or late sign of humoral rejection is of the greatest importance for evaluation of assays for these antibodies and for therapeutics. If donor-specific antibodies can be detected reliably early in the course or even prior to rejection, then one can soundly test whether a given intervention prevents or reverses rejection. And if, as some believe, "non-compliance" with immunosuppressive therapy sparks many episodes of rejection, then donor-specific antibodies might provide a useful index of compliance with treatment and hence susceptibility to rejection. However, if donor-specific antibodies are not detected until severe tissue injury ensues, then failure of a given intervention might reflect the advanced stage of injury at the time the intervention was tested and any usefulness of these antibodies as an index of compliance would be quite limited.

\section{Are donor-specific antibodies donor specific?}

While we have little experience with the various assays used for human donor-specific antibodies, we can share here some questions that our experimental work might suggest. One question we would pose is whether and to what extent the measured antibodies represent antibodies that might perturb a graft. If a transplant absorbs donor-specific antibodies to any extent, the absorbed antibodies will likely be of higher affinity and greater pathogenicity than antibodies remaining in the blood. The biologic properties of antibodies in the graft might also differ from those in the blood. For example, we showed that antibodies that activate complement inefficiently can potentially block complement-fixing antibodies from binding to cellular targets (13); if one or another of these fractions bound to the graft, the remaining antibodies would have the opposite function of the bound antibodies. Such competition might also influence assays of specificity. Because binding of an antibody against one antigen can sterically hinder binding of an antibody against another antigen, we would question whether the specificity of donor-specific antibodies in the blood of transplant recipients differs from or represents the specificity of antibodies bound to the graft. This question is especially important for assays in which antigenic 
targets are segregated on microspheres, because the microspheres do not permit competition for binding that occurs on cell surfaces. On cells, antibodies against one or a few HLA might occupy the available surface, sterically blocking the binding of antibodies against other HLA. In this setting, analysis of the blood would reveal antibodies against HLA to which antibodies were not bound in preference to antibodies against HLA to which antibodies were actually bound.

\section{Do donor-specific antibodies measure immunity or inflamation?}

Antibody production is stimulated by antigen plus co-stimulation but also by inflammation (14, 15). Where antibody responses are driven by antigen, one can induce tolerance or at least longstanding non-responsiveness in antigen-specific ways as can be performed for immunity to coagulation factor VIII $(16,17)$. On the other hand, where inflammation drives antibody production, these approaches might induce immunity or immunodeficiency. As antigen-specific and antigen-non-specific stimulation induce comparable B-cell responses (in vitro) measuring donor-specific antibodies alone cannot answer this question.

As interested as we are in knowing whether donor-specific antibodies are produced after transplantation, we are equally interested in knowing whether antibodies against antigens not carried by the graft are produced after transplantation. If antibodies against other antigens increase in a given setting, then one might consider two further questions: are donor-specific antibodies (and donor non-specific antibodies) responding to inflammation and if so do they predict immune responsiveness in a general sense; and does this general capacity to mount an immune response rather than donor specificity confer heightened risk of rejection and a bad outcome of transplantation? Perhaps in these cases, therapeutics directed at inflammation and inflammatory agonists might be found to be of use.

\section{Are donor-specific antibodies always noxious?}

Antibodies against a donor, and even antibodies against other targets, can potentially regulate immunity and protect against tissue injury (18). Donor-specific antibodies can cause enhancement of certain grafts including renal allografts by blocking interaction of donor antigen with recipient lymphocytes (19). This phenomenon has been called enhancement because it was first observed as enhanced lethality of allogeneic tumor grafts (20). Although the phenomenon of enhancement is supported by an abundance of experimental and clinical experience, it has been largely ignored in recent years, perhaps because one cannot reliably use the phenomenon in therapeutics. In contrast to antibody-mediated tissue injury, which may vary with antibody levels, enhancement seems to reflect antigen density more than antibody concentration (18). To the extent that enhancement reflects blocking or suppression of cellular immunity, one might envision using donor-specific antibodies to test whether absence of rejection in subjects with detectable antibodies results from such blocking or suppression.

Antibodies against a donor can also induce accommodation (21): a condition in which a graft appears to acquire resistance to humoral injury. We have reviewed the subject of accommodation elsewhere $(22,23)$ and will not undertake to do so here. Rather, we would use the occasion of this communication to stress that the challenge of detecting donor-specific antibodies may be key for identifying and better understanding the accommodation.

Accommodation differs from tolerance and enhancement in that it requires an immune response that is potentially toxic for a graft (tolerance and enhancement and immunosuppression prevent such responses). We have been concerned that some and possibly many cases of accommodation are not detected because donorspecific antibodies are absorbed to the graft as discussed earlier. This possibility is illustrated in Figs. 1 and 2. If donor-specific antibodies can induce accommodation, then one would want to consider the benefit of that condition vs. the risk of rejection, testing strategies for depleting those antibodies, or inhibiting their production. To the extent that donor-specific antibodies might induce protection via the target antigen, as some work suggests $(24,25)$, the specificity and/or function of these antibodies is key for determining whether they cause harm or benefit. Further, we have postulated that accommodation itself may not be entirely beneficial and indeed may potentially explain, and even cause, chronic rejection $(26,27)$. In this setting too, a further understanding of the biology of donor-specific antibodies might help refine our understanding of risk and therapeutics.

\section{Concluding remarks}

As basic scientists, we are stimulated by the current interest in applying new technologies for measuring of donor-specific antibodies in transplantation. We think that work in this area could 
shed light on the development and regulation of immunity and the impact of immunity on targeted tissues. These insights might come from thoughtful analysis of existing information but most likely will require laboratory and clinical efforts that extend beyond the analyses immediately at hand. Clinical research seems often to be limited by reliance on correlations (donor-specific antibodies correlate with antibody-mediated rejection but do the measured antibodies cause or are they simply the residua of loss of perfusion?). However, in clinical transplantation, one can potentially access the target of immunity (the graft) and the immune system of the recipient before and after exposure to antigen and test for the impact of genes yet to be implicated in the functions of the immune system. And, when the value of an assay, such as donor-specific antibodies, is proved, one can test whether that assay can rank individuals for immunologic function. Such opportunities are not to be exploited in experimental systems because these systems, particularly the inbred strains of mice, were developed by selection based on rejection and because the genetic manipulations on which we rely inevitably generate compensatory phenotypes, which we make every effort to ignore.

\section{Acknowledgment}

Work in the authors' laboratory is supported by grants from the National Institutes of Health (HL52297, HL79067).

\section{References}

1. Kissmeyer-Nielsen F, Olsen S, Petersen VP, Fueldborg O. Hyperacute rejection of kidney allografts, associated with preexisting humoral antibodies against donor cells. Lancet 1966: 2 : 662-665.

2. Vlad G, Ho EK, Vasilescu ER, et al. Relevance of different antibody detection methods for the prediction of antibodymediated rejection and deceased-donor kidney allograft survival. Hum Immunol 2009: 70: 589-594.

3. Cascalho M, Platt JL. Basic mechanisms of humoral rejection. Pediatr Transplant 2005: 9: 9-16.

4. Cascalho M, Platt JL. The immunological barrier to xenotransplantation. Immunity 2001: 14: 437-446.

5. Gorer P. The genetic and antigentic basis of tumor transplantation. J Pathol Bacteriol 1937: 44: 691-697.

6. Gorer PA, Lyman S, Snell GD. Studies on the genetic and antigenic basis of tumour transplantation. Linkage between a histocompatibility gene and "fused" in mice. Proc R Soc Lond B Biol Sci 1948: 135: 499-505.

7. Farney aC, Matas AJ, Noreen HJ, et al. Does re-exposure to mismatched HLA antigens decrease renal re-transplant allograft survival? Clin Transplant 1996: 10: 147-156.

8. Collins BH, Cotterell AH, McCurry KR, et al. Cardiac xenografts between primate species provide evidence for the importance of the alpha-galactosyl determinant in hyperacute rejection. J Immunol 1995: 154: 5500-5510.

9. Galili U, Macher BA, Buehler J, Shohet SB. Human natural anti- $\alpha$-galactosyl IgG. II. the specific recognition of $\alpha$ (1-3)-linked glactose residues. J Exp Med 1985: 162: 573-582.

10. Lin SS, Weidner BC, Byrne GW, et al. The role of antibodies in acute vascular rejection of pig-to-baboon cardiac transplants. J Clin Invest 1998: 101: 1745-1756.

11. Lin SS, Hanaway MJ, GonZalez-Stawinski GV, et al. The role of anti-Gal $\alpha 1-3 \mathrm{Gal}$ antibodies in acute vascular rejection and accommodation of xenografts. Transplantation 2000: 70: 1667-1674.

12. Carpenter CB, D'Apice AJ, Abbas AK. The role of antibodies in the rejection and enhancement of organ allografts. Adv Immunol 1976: 22: 1-65.

13. Yu PB, Holzknecht ZE, Bruno D, Parker W, Platt Jl. Modulation of natural IgM binding and complement activation by natural IgG antibodies. J Immunol 1996: 157: $5163-$ 5168.

14. Nossal GJ. Kinetics of antibody formation and regulatory aspects of immunity. Acta Endocrinol Suppl (Copenh) 1975: 194: 96-116.

15. Nossal GJ. The Florey lecture, 1986. The regulatory biology of antibody formation. Proc R Soc Lond B Biol Sci 1986: 228: 225-240.

16. White GC II, TAylor RE, Blatt PM, Roberts HR. Treatment of a high titer anti-factor-VIII antibody by continuous factor VIII administration: Report of a case. Blood 1983: 62: 141145.

17. Nilsson IM, Berntorp E, Zettervall O. Induction of immune tolerance in patients with hemophilia and antibodies to factor VIII by combined treatment with intravenous IgG, cyclophosphamide, and factor VIII. N Engl J Med 1988: 318: 947-950.

18. Platt JL. Antibodies in transplantation. Discov Med 2010: 10: $125-133$.

19. Morris PJ. Suppression of rejection of organ allografts by alloantibody. Immunol Rev 1980: 49: 93-125.

20. Kaliss N. The elements of enhancement: A consideration of mechanisms. Ann N Y Acad Sci 1962: 101: 64-79.

21. Platt Jl, Vercellotti GM, Dalmasso AP, et al. Transplantation of discordant xenografts: A review of progress. Immunol Today 1990: 11: 450-456.

22. Lynch RJ, Platt JL. Accommodation in organ transplantation. Curr Opin Organ Transplant 2008: 13: 165-170.

23. LynCh RJ, Platt JL. Escaping from rejection. Transplantation 2009: 88: 1233-1266.

24. Jindra PT, Zhang X, Mulder A, et al. Anti-HLA antibodies can induce endothelial cell survival or proliferation depending on their concentration. Transplantation 2006: 82: S33-S35.

25. Jindra PT, Hsueh A, Hong L, et al. Anti-MHC class I antibody activation of proliferation and survival signaling in murine cardiac allografts. J Immunol 2008: 180: 2214-2224.

26. Platt JL, Nath KA. Heme oxygenase: Protective gene or Trojan horse. Nat Med 1998: 4: 1364-1365.

27. Platt JL. C4d and the fate of organ allografts. J Am Soc Nephrol 2002: 13: 2417-2419.

28. McCurry KR, Parker W, Cotterell AH, et al. Humoral responses in pig-to-baboon cardiac transplantation: Implications for the pathogenesis and treatment of acute vascular rejection and for accommodation. Hum Immunol 1997: 58: 91105. 